\title{
Mobitz Type II Atrioventricular Heart Block After Candlenut Ingestion
}

Andrew L. Koons, DO; Lexis T. Laubach, BS; Kenneth D. Katz, MD; Gillian A. Beauchamp, MD

From the Lehigh Valley Health Network, Department of Emergency and Hospital Medicine / USF Morsani College of Medicine in Allentown, Pennsylvania.

Financial Disclosures: None reported.

Support: None reported. Address correspondence to Andrew L. Koons, DO, LVH-M

4th Floor (South Wing), 2545 Schoenersville Road, Bethlehem, Pennsylvania, 18017-7300.

Email:

andrew.koons@lvhn.org

Submitted

February 17, 2020;

revision received

June 26, 2020;

accepted

July 6, 2020.
The candlenut is a highly accessible seed marketed as a natural weight-loss supplement. However, there is little known about the exact mechanism of action for weight loss nor for the many adverse symptoms it causes, such as nausea, vomiting, fatigue, cardiac dysrhythmias, and even death. In this case report, the authors present a 44-year-old woman who developed a seconddegree, Mobitz type II atrioventricular block after consumption of a candlenut supplement. She presented to the emergency department with syncope and her cardiac rhythm indicated a second-degree heart block soon after ingesting candlenuts recommended by her treating physician. Interestingly, a detectable digoxin concentration obtained on hospital day 2 was measured but of unclear significance given no obvious exposure to a cardioactive glycoside. The patient's rhythm normalized on hospital day 2 and she was discharged uneventfully.

J Am Osteopath Assoc. 2020;120(12):839-843. Published online October 5, 2020. doi:10.7556/jaoa.2020.136

Keywords: adverse drug effects, candlenut, heart block, ingestion

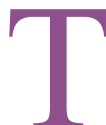
he candlenut (Aleurites moluccanas) is marketed as a natural weight-loss supplement, although relatively little is known about its mechanism of action. It is highly accessible due to its sale on common websites as a raw seed or in capsules. Its purported therapeutic effects include weight loss and cholesterol reduction, as well as management of alopecia, cellulite, and tobacco use disorder. ${ }^{1}$ Subroto et $\mathrm{al}^{2}$ analyzed the composition of candlenut oil and found a high content of oleic acid, linoleic acid, and linolenic acid, all of which have health benefits. However, Gonzalez-Stuart et $\mathrm{al}^{1}$ advised that no part of the seed be consumed because of bioactive ingredients that are cocarcinogenic and act as strong laxatives.

Candlenut use has resulted in multiple adverse symptoms, including headache, nausea, vomiting, diarrhea, fatigue, cardiac dysrhythmias, and 3 reported deaths. ${ }^{3}$ One case report ${ }^{4}$ described a woman whose electrocardiogram (ECG) revealed evidence of bradycardia and a first-degree atrioventricular (AV) heart block after candlenut consumption. These harmful effects have led to its ban in Argentina, Spain, Brazil, and other South American countries. ${ }^{1,3,5}$ We found no other reported cases of a second-degree, Mobitz type II AV block after candlenut consumption, which we describe here. 


\section{Report of Case}

A 44-year-old woman with no significant prior medical history and no currently-prescribed medications presented to the emergency department (ED) with altered mental status; she was only responsive to sternal rub. Minutes after presentation, she was hyperventilating and responsive enough to report numbness in her face, tongue, and arms. Over the next several hours, her mental status returned to baseline. She reported having recently lost 46 pounds after being on a strict, selfmonitored weight loss regimen for 2 months; the patient was consuming only lettuce, meat, and water. She discussed her weight loss with her family doctor, who suggested she take an over-the-counter Brazilian candlenut weight loss supplement. She began to take "1 small piece" per day, 2 days prior to ED arrival. She immediately began experiencing abdominal pain, progressing to diarrhea on the second day. On the day of her presentation to the $\mathrm{ED}$, she reported vomiting, generalized weakness, palpitations, chest discomfort, and shortness of breath. An ECG showed a second-degree AV heart block with characteristic shortened QT interval with ST-T changes consistent with digitalis effect (Figure 1). The patient's vital signs and initial electrolytes, renal function, serum troponin, urine drug screen, and complete blood count were all unremarkable. No maneuvers (such as carotid massage) or pharmacologic interventions were made to correct the bradycardia.

The patient was admitted to the hospital for monitoring. During her admission, she received intravenous fluids and pantoprazole, oral sucralfate, and a clear liquid diet. The following morning, a repeat ECG was performed, which continued to show AV block with increased sinus rate (Figure 2). The AV block resolved on hospital day (HD) 2. There were no reported AV block variations and the abnormal rhythm corrected to normal sinus rhythm without any intervening rhythm disturbances. This finding was confirmed on telemetry, and the patient's rhythm strip before discharge is shown (Figure 3). A digoxin concentration on HD 2 measured $0.3 \mathrm{ng} / \mathrm{mL}$. This concentration was not repeated. The patient was discharged in good health on HD 2 and asked not to consume candlenut.

\section{Discussion}

In most reported cases, previously-reported symptoms of candlenut were either general constitutional or

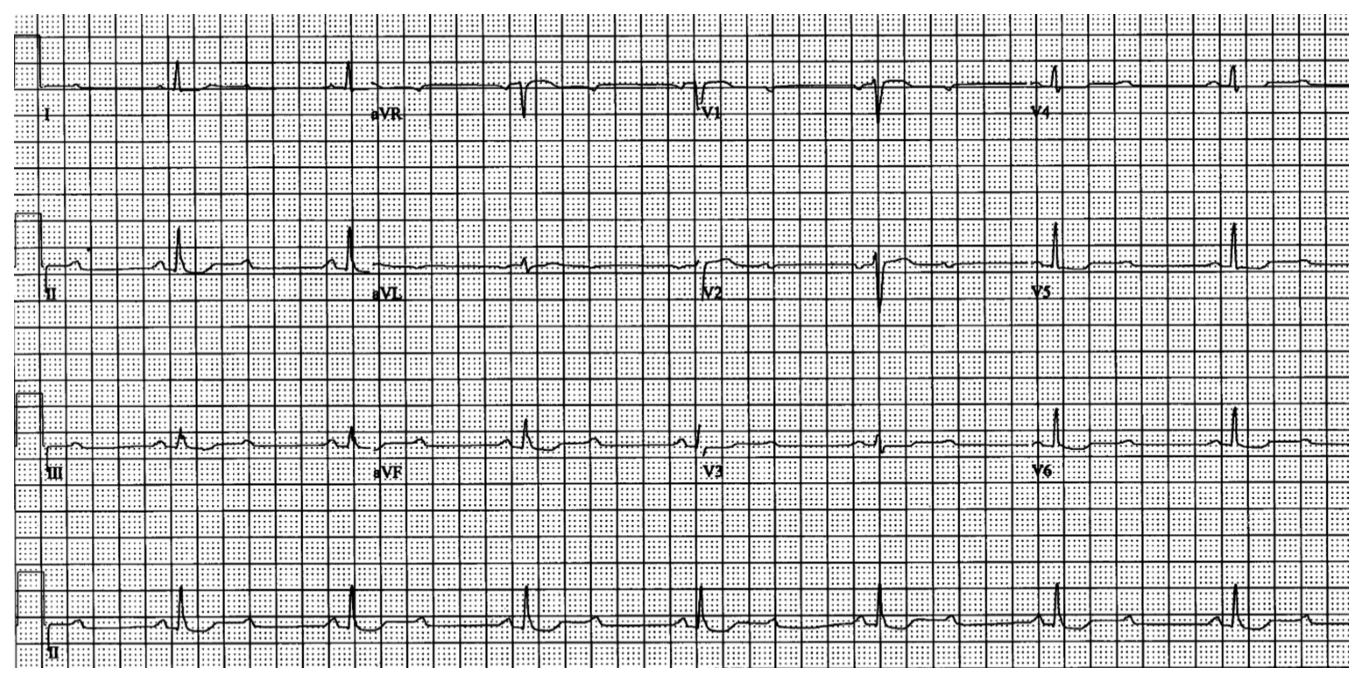

Figure 1.

Upon presentation to the emergency department, the patient's initial electrocardiogram showed Mobitz Type II AV heart block with characteristic shortened QT interval with ST-T changes consistent with digitalis effect. 


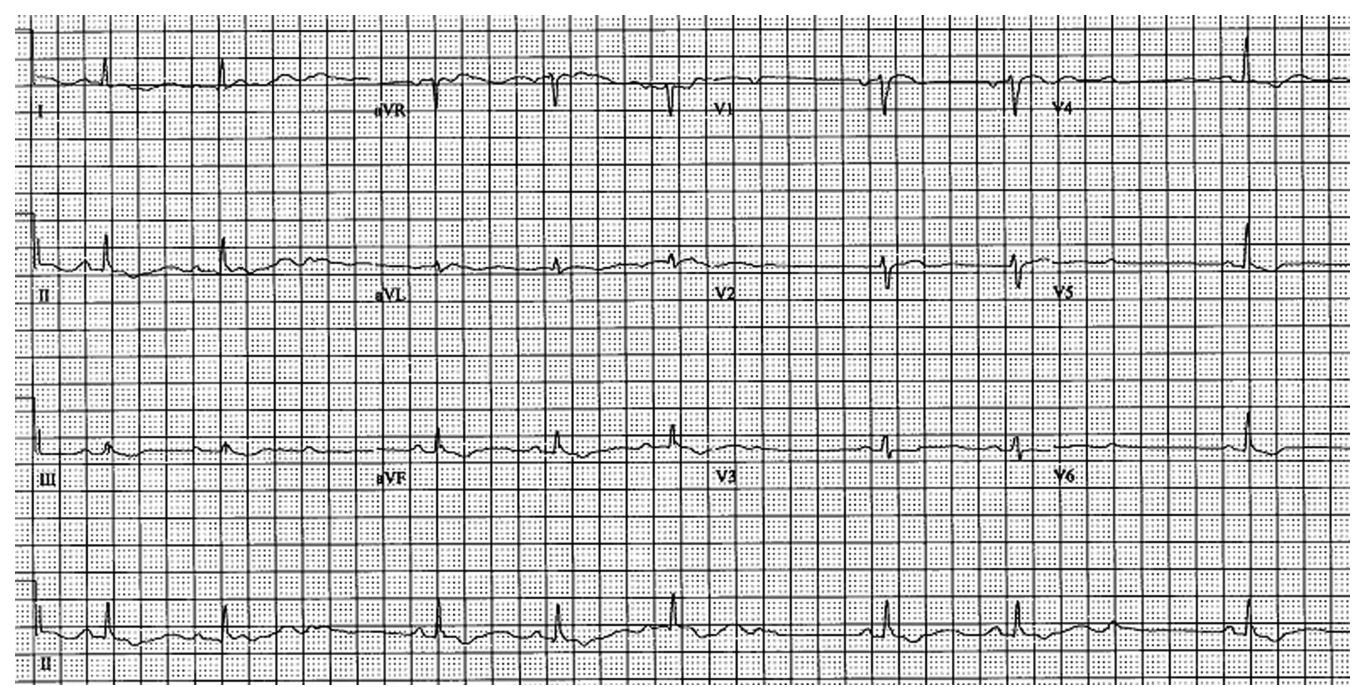

Figure 2.

The patient's electrocardiogram from the day after admission showed continued Mobitz Type II AV heart block with increased sinus rate.

gastrointestinal in nature. ${ }^{1,6}$ Rarely, cases involving cardiac abnormalities have been reported, ${ }^{3}$ including descriptions of bradycardia ${ }^{5}$ and first-degree $\mathrm{AV}$ block. ${ }^{1}$ One previous report from Spain in $2017^{1}$ described a very similar case of a patient with elevated digoxin concentration after candlenut ingestion.

$\mathrm{AV}$ heart block occurs when there is a disruption in normal impulse conduction through the heart. Normal electrical conduction will begin at the sinoatrial (SA) node, disseminate throughout the atria, collect at the AV node, travel down to the bundle of His and the bundle branches, then propagate along the Purkinje fibers in the ventricles. Conduction failure can occur both at the AV node and infranodally. However, most Mobitz type II blocks in humans occur from infranodal disruption. ${ }^{6} \mathrm{AV}$ heart blocks can manifest from ischemia, drug toxicity, hyperkalemia, excessive vagal stimulation, cardiac valvular calcification, myocarditis, or infiltrative cardiomyopathy. ${ }^{7,8}$

The mechanism by which the candlenut causes toxicity is largely unknown. However, phorbol esters are present in candlenuts, which can cause diarrhea, vomiting, and polyuria. ${ }^{1}$ Phorbol esters also have cocarcinogenic effects, mimicking the action of diacylglycerol in the body, which then promotes protein kinase $\mathrm{C}$ (PKC) activity. ${ }^{9}$ This increase of PKC activity in the presence of another carcinogen aids in promoting a tumor's growth. PKC activation is also responsible for some of the inflammatory effects of candlenut. ${ }^{9}$ The etiology of heart blocks secondary to

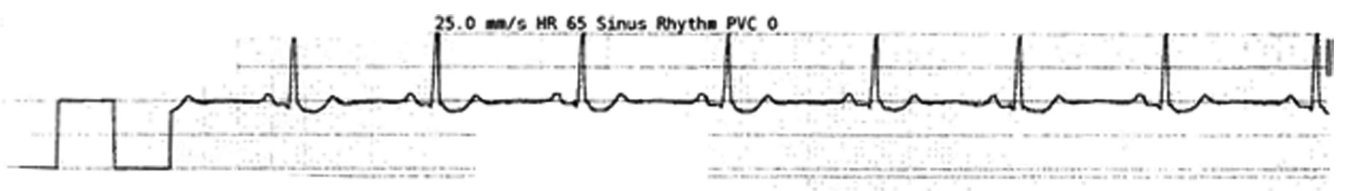

Figure 3.

The patient's rhythm strip before discharge from the hospital showed a return to normal sinus rhythm with continued ST-T changes consistent with digitalis effect. 
candlenut ingestion, however, remains enigmatic. A digoxin concentration measured on HD 2 in our patient was detectable, but the patient denied any exogenous cardioactive steroid exposure. Moreover, there was no suspicion of endogenous digoxin-like immunoreactive substances in this otherwise healthy patient. Plant-based cardioactive steroids can crossreact with digoxin assay, which assists in making a presumptive diagnosis of nonpharmaceutical cardioactive steroid exposure. ${ }^{10-12}$ It is unknown whether candlenut exposure could, in fact, cause a falsely-elevated serum digoxin concentration. Potential adulterants in unregulated supplements could also cause the described adverse effects and toxicities. In this case, the presence of a detectable digoxin concentration may be indicative of a cardioactive steroid-based adulterant, contaminant, or component of the candlenut.

There are several limitations to a case study based on a patient's subjective report of what she may have ingested, including but not limited to a lack of reliability for the timing of ingestion, recall of exactly what was ingested, and other exact details of her recent history. There may also be a component of social desirability bias, as the patient may have been taking another medication or supplement that she did not report. Furthermore, we had no previous records of this patient to know what her baseline psychiatric or cardiac history may have been. She also did not bring a sample of the actual product to the hospital and we were unable to obtain it afterward. We do not know how the candlenut product was processed before it was ingested. There was also no expanded or confirmatory drug screening done at the hospital for this patient. Although absolute confirmation of exposure was impossible, the temporal relationship of symptom development abruptly after exposure to candlenut with cessation quickly thereafter, without any other obvious etiology, lend credence to candlenut toxicity. Though we cannot definitively claim causality, there seems to be an association with this patient's ingestion of candlenut supplement and her presentation.

\section{Conclusion}

Although the mechanism of action for this patient's second-degree, Mobitz type II AV hear block after candlenut ingestion is unclear, this report serves not only as a warning about the risks unregulated supplements, but also as a reminder about the importance of taking a complete patient history, including inquiry about nonprescribed medications. Further study is required to elucidate the cardioactive components of the candlenut.

\section{Acknowledgments}

The authors would like to specifically thank the following toxicology colleagues who helped in the preparation of this case report: Alexandra M. Amaducci, DO; Robert D. Cannon, DO; Ryan M. Surmaitis, DO; Matthew D. Cook, DO.

\section{Author Contributions}

Ms Laubach provided substantial contributions to conception and design, acquisition of data, or analysis and interpretation of data; Dr Koons drafted the article or revised it critically for important intellectual content; Drs Beauchamp and Katz gave final approval of the version of the article to be published; and all authors agree to be accountable for all aspects of the work in ensuring that questions related to the accuracy or integrity of any part of the work are appropriately investigated and resolved.

\section{References}

1. González-Stuart AE, Ortíz Rivera J. Toxicity of candlenut seed (aleurites moluccanus), a purported herbal weight loss supplement. Pharmacologia. 2017;8:25-31. doi:10.5567/pharmacologia.2017.25.31

2. Subroto E, Widjojokusumo E, Veriansyah B, Tjandrawinata RR Supercritical $\mathrm{CO} 2$ extraction of candlenut oil: process optimization using taguchi orthogonal array and physicochemical properties of the oil. J Food Sci Technol. 2017;54(5):1286-1292. doi:10.1007/ s13197-017-2542-7

3. Ahora. Nuez de la India, la semilla dietética que puede provocar la muerte. Published March 10, 2017. Accessed October 15, 2019. https://ahora.com.ar/nuez-la-india-la-semilla-dietetica-que-puedeprovocar-la-muerten390835.

4. Pinillos MA, Beaumont C, Louis CJ, et al. Intoxicacion por "nuez de la india" (aleurites moluccana). Revista de Toxicologia. 2007:24(2-3):83.

5. Agencia Nacional de Regulacion, Control, y Vigilanica Sanitaria. Se reitera peligro de ingerir nuez de la India o productos que la contengan. Published July 2, 2017. Accessed October 15, 2019. https://www.controlsanitario.gob.ec/se-reitera-peligro-de-ingerir-nuezde-la-india-o-productos-que-lacontengan/.

6. Nelson LS, Balick MJ. Section 5: Individual Plants. In: Handbook of Poisonous and Injurious Plants.

7. Spear JF, Neil Moore E. Electrophysiologic studies on mobitz type ii second-degree heart block. Circulation. 1971;44:1087-1095.

8. Wogan JM, Lowenstein SR, Gordon GS. Second-degree atrioventricular block: mobitz type II. J Em Med. 1993;11(1):47-54 
9. Goel G, Makkar HPS, Francis G, Becker K. Phorbol esters: structure, biological activity, and toxicity in animals. Int J Toxicol. 2007;26:279-288. doi:10.1080/10915810701464641

10. Cheung K, Hinds JA, Duffy P. Detection of poisoning by plant-origin cardiac glycoside with the abbott tdx analyzer. Clin Chem. 1989;35 (2):295-297.
11. Radford DJ, Cheung $\mathrm{K}$, Urech $\mathrm{R}$, et al. Immunological detection of cardiac glycosides in plants. Aust Vet J. 1994;71(8):236-238.

12. Graves SW. Endogenous digitalis-like factors. Crit Rev Clin Lab Sci. 1986;23:177-200.

๑) 2020 American Osteopathic Association 